\title{
TU/e EmonONEN

\section{EBG enhanced dielectric lens antennas for the imaging at sub-mm waves}

\section{Citation for published version (APA):}

Neto, A., Bekers, D. J., Gerini, G., Baselmans, J. J. A., Yates, S., \& Hoevers, H. F. C. (2008). EBG enhanced dielectric lens antennas for the imaging at sub-mm waves. In Proceedings of IEEE Antennas and Propagation Society International Symposium, 2008, AP-S 2008, 5-11 July 2008, San Diego, CA (pp. 1-4). Institute of Electrical and Electronics Engineers. https://doi.org/10.1109/APS.2008.4619323

DOI:

10.1109/APS.2008.4619323

Document status and date:

Published: 01/01/2008

\section{Document Version:}

Publisher's PDF, also known as Version of Record (includes final page, issue and volume numbers)

\section{Please check the document version of this publication:}

- A submitted manuscript is the version of the article upon submission and before peer-review. There can be important differences between the submitted version and the official published version of record. People interested in the research are advised to contact the author for the final version of the publication, or visit the DOI to the publisher's website.

- The final author version and the galley proof are versions of the publication after peer review.

- The final published version features the final layout of the paper including the volume, issue and page numbers.

Link to publication

\section{General rights}

Copyright and moral rights for the publications made accessible in the public portal are retained by the authors and/or other copyright owners and it is a condition of accessing publications that users recognise and abide by the legal requirements associated with these rights.

- Users may download and print one copy of any publication from the public portal for the purpose of private study or research.

- You may not further distribute the material or use it for any profit-making activity or commercial gain

- You may freely distribute the URL identifying the publication in the public portal.

If the publication is distributed under the terms of Article 25fa of the Dutch Copyright Act, indicated by the "Taverne" license above, please follow below link for the End User Agreement:

www.tue.nl/taverne

Take down policy

If you believe that this document breaches copyright please contact us at:

openaccess@tue.nl

providing details and we will investigate your claim. 


\title{
EBG Enhanced Dielectric Lens Antennas for the Imaging at Sub-mm Waves
}

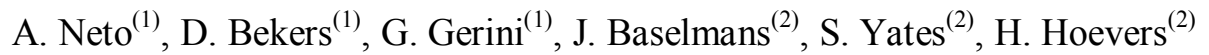

(1) TNO - Defence, Security and Safety, Oude Waalsdorperweg 63, 2597 AK, The Hague, The Netherlands. E-mail : andrea.neto, dave.bekers, giampiero.gerini@tno.nl (2) SRON Netherlands Institute for Space Research, Sorbonnelaan 2, 3584CA Utrecht, The Netherlands, E-mail: J.Baselmans@,sron.nl, $\quad \underline{\text { S.Yates@,sron.nl, }}$ H.F.C.Hoevers@sron.nl

\section{Introduction}

Truly integrated antennas in $\mathrm{mm}$ and sub- $\mathrm{mm}$ wave regimes can be realized by printing planar radiating elements in the focal plane of elliptical or extended hemispherical lens antennas [1], [2]. The elliptical shape of the lens gives high focusing properties provided that its eccentricity is properly related to its dielectric constant $\left(\mathrm{e}=1 / \varepsilon^{1 / 2} \mathrm{r}\right)$. In the frame of cooperation activity between TNO and SRON, the main purpose of this contribution is to present a new way to increase the directivity of the focal plane feeds typically used to excite such lenses. The driving reason for this effort is the desire to diminish the impact of the reflections at the dielectric air interface when these structures are proposed as focal plane imagers.

The number of elements that can be located in the focal plane of a dielectric lens is limited because the performances of the elements located at a large distance from the central focus are significantly degraded with respect to the elements in focus $[3]$.
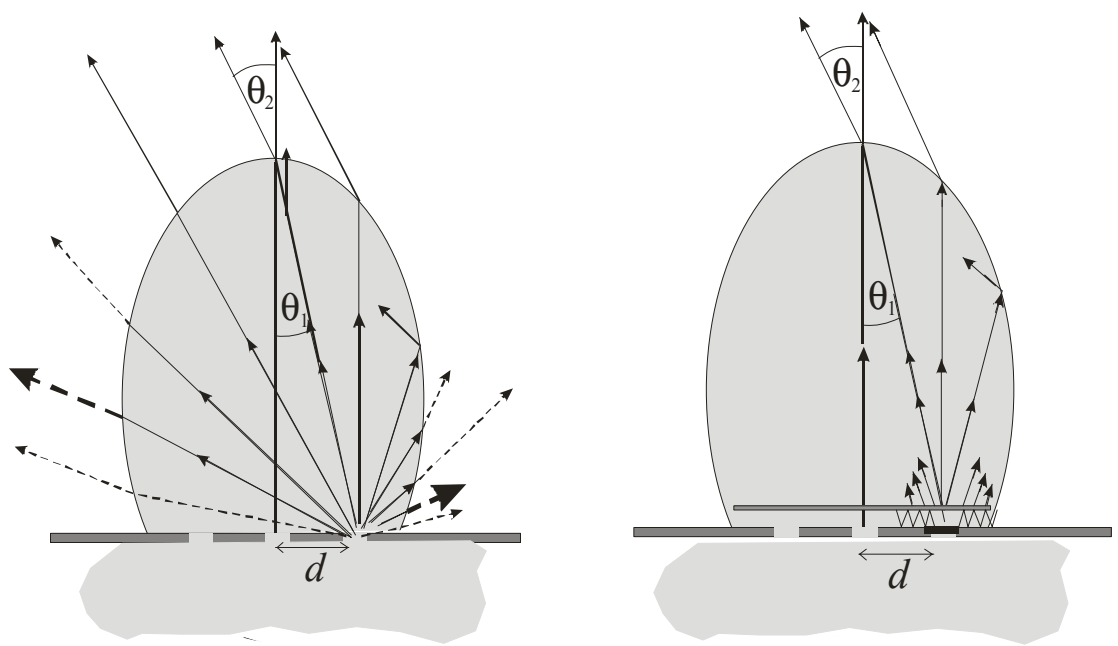

Fig. 1 Ray picture in the case of an off focus fed dielectric lens, with and without leaky wave enhancement by means of EBG super-layer.

This effect can be interpreted as low spill-over efficiency of the lens since a significant portion of the power radiated by the feeds is intercepted by the dielectric-to-air interface at locations that do not directly contribute to a focused beam. To increase the number of radiators on the ground plane, elements of larger directivity should be used so that they all excite efficiently the central portion of the lens is larger. This solution is effectively equivalent to increasing the F/D of the lens system. 


\section{EBG Enhanced Dielectric Lenses}

Recent investigations indicate that Electromagnetic Band Gap (EBG) super-layers can be used to enhance the directivity of planar and waveguide antennas. In particular, in [4] and [5], the efficient excitation of reflector antennas by means of EBG enhanced printed waveguide feeds has been discussed in depth. The main result is that the efficiency of single-feed reflectors and imaging arrays can be increased significantly with respect to radiators operating in free space, at low to moderate manufacturing cost. Here a similar design strategy has been applied to increase the efficiency of dielectric lens antennas. While the use of EBG super-layers at microwave frequencies was justified mainly by the electric performances of the systems, the manufacturing advantages of the EBG solutions based on dielectric may end up being the most important criteria in the sub-mm wave regimes. This particular difference can be understood from the intrinsic difficulty in realizing corrugated waveguide horns with micrometric accuracies and the integration of these horns with the receivers could be insurmountable.

\section{Inverted Dielectric stratification.}

The guidelines for a dielectric stratification to realize the optimal Fabry-Perot resonator, also referred to as EBG structure, have been clarified to the antenna community by Jackson and Oliner in [6], who provided a leaky-wave interpretation of the phenomenon. Two dominant (TE/TM) leaky waves are sufficient to represent main radiation in directions close to broadside. If the upper layer is a dielectric lens antenna (Fig. 2b) instead of free space (Fig. 2a), a series of quarter wavelength transformers will create an equivalent input impedance $z_{\text {in }}$ that is very large instead of very small. In this way, a virtual open circuit or magnetic conductor is created. As depicted in Fig. 2 (b), layer ( 0 ) is then a quarter of the dielectric wavelength, shorted by a ground plane at $z=0$. Consequently, the field configuration of a waveguide with a lower electric wall and an upper magnetic wall is created. At every bounce in the positive $\mathrm{z}$ direction there is some power leaked in higher stratifications which eventually leads to radiation in the dielectric.

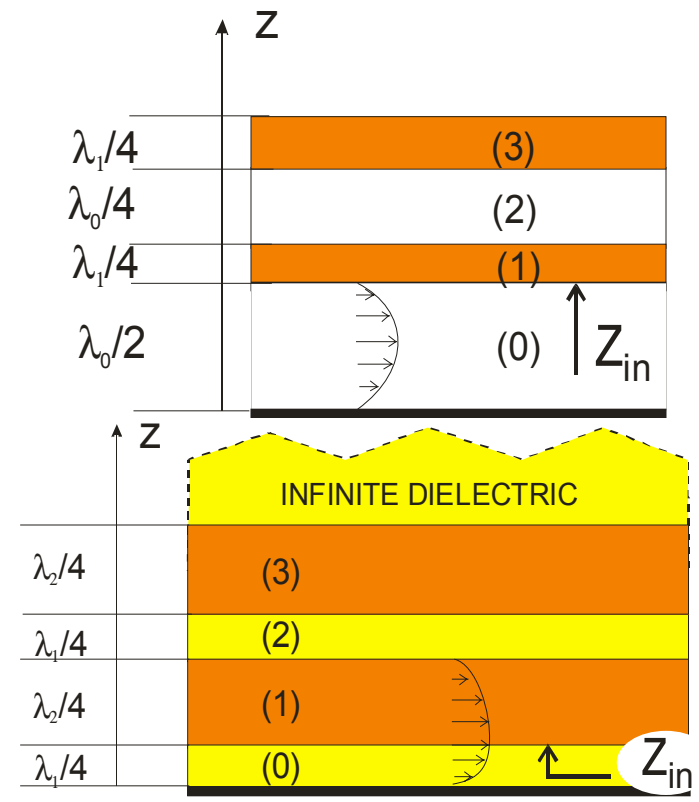

(a)

(b)

Fig.2 Dielectric stratification to achieve directivity enhancement for a structure radiating in free space, $2 \mathrm{a}$, and for a structure radiating inside an infinite dielectric, $2 \mathrm{~b}$. 


\section{Design of the printed radiators}

The wave picture just described can be rigorously represented by identifying the two dominant poles in the Green's Function of the dielectric stratification. The directivity enhancement that can be achieved depends on the equivalent impedance contrast which is observed at $z_{\text {in }}$. Given a fixed ratio between $\varepsilon_{\mathrm{r} 1}$ and $\varepsilon_{\mathrm{r} 2}$ such contrast can be enhanced to achieve higher directivities by using a larger number of dielectric superlayers. However, such an increase of contrast leads to a smaller operating BW.

The trade-off between the BW and the directivity guides our design, in which only one layer of dielectric constant $\varepsilon_{\mathrm{r} 1}=4$ (quartz) is applied to enhance the radiation in the lens of $\varepsilon_{\mathrm{r} 2}=11.7$ (silicon). For our design, we decided to initially choose $10 \mathrm{GHz}$ as design frequency, for which we had already acquired experience in [5]. Accordingly the lower slabs are $2.4 \mathrm{~mm}$ for the silicon layer and $3.75 \mathrm{~mm}$ for the quartz layer. A double slot radiator is designed, see Fig. 3a. The central radius (Rin+Rout) $/ 2$ of this slot is set in such a way that an optimal excitation of the lens is achieved by minimizing the influence of higher order modes as in [4]. The width of the slots affects their impedance bandwidth while the length of each arc (defined by the angle $\alpha$ ) sets the central operating frequency. A nominal design with slabs tuned to $10 \mathrm{GHz}$ operates well on a $10 \% \mathrm{BW}$ centered around $10.5 \mathrm{GHz}$ for the following parameter choices: Rin=2.6 mm, Rout $=3.2 \mathrm{~mm}, \mathrm{a}=22^{\circ}$.
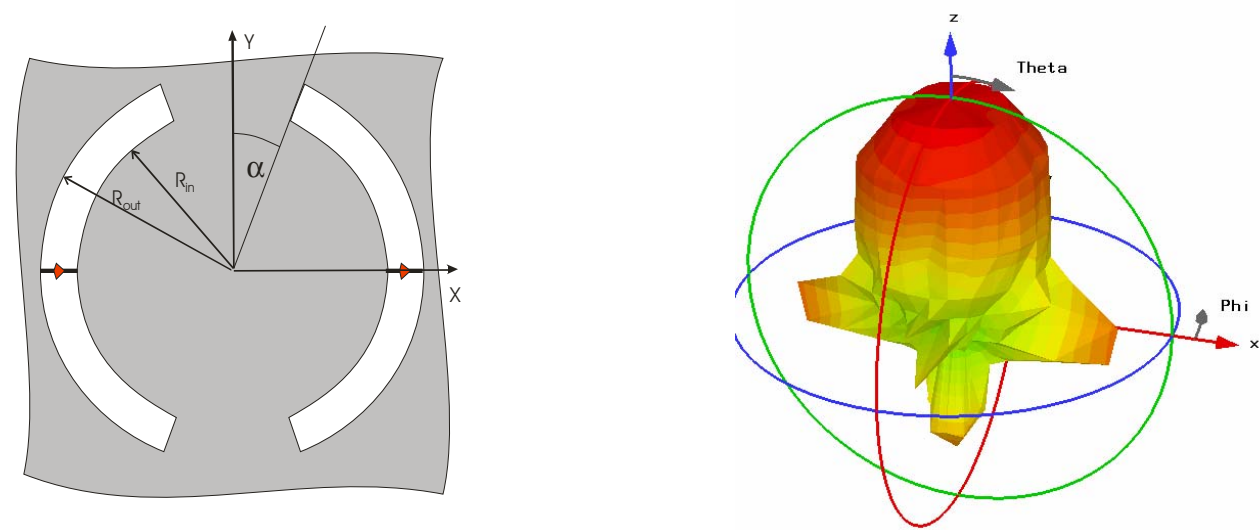

Fig. 3 Double slot configuration a) to achieve symmetric patterns b) and cancellation of higher order modes

The radiation pattern of the double-slot structure calculated at $10.5 \mathrm{Ghz}$ with the commercial CST (FDTD) is presented in Fig. 3b. One can observe the almost perfect symmetry of the pattern as a function of the azimuth angle as well as the rapid dropoff, which starts at about $30^{\circ}$. These properties ensure that the silicon dielectric lens excited by the twin slot will have a high spill-over efficiency.

\section{Sub-mm wave Implementation}

After the preliminary design at $10.5 \mathrm{GHz}$, a prototype of an antenna system was manufactured for operation at $670 \mathrm{GHz}$. This prototype consists of the (scaled) antenna integrated with a Kinetic Inductance Detector (KID), as currently developed by SRON. The main purpose of this integration is to demonstrate the effectiveness of the detector in combination with a leaky-wave enhanced antenna. We need to mention here that, for the time being, KIDs are realized with a technology based on the use of a dielectric slab that hosts a metallic printed structure. Since such a structure will have to host both the slot antennas and the feeding structure, the only available solution is to use 
coplanar waveguide (CPW) feeding lines. Each of the two slots is therefore excited with a CPW line and the two lines are connected in parallel to achieve a unique feed. The input reflection coefficient present at the common feed point by this feed arrangement with a CPW line of 50 Ohm impedance is shown in Fig. 4

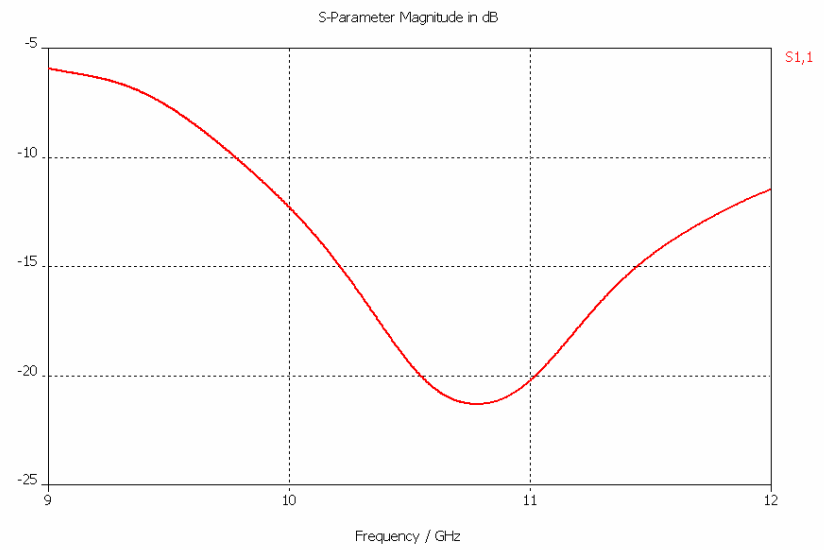

Fig. 4 Reflection coefficient at the common input CPW line (50 Ohm).

The results of the manufacturing at $670 \mathrm{GHz}$ and the measurement campaign that includes secondary radiation patterns and coupling efficiencies to the receivers will be shown during the oral presentation.

\section{References}

1. D.F. Filippovic, S.S. Gearhart, and G. M. Rebeiz: "Double Slot on Extended Hemispherical and Elliptical Silicon Dielectric Lenses" IEEE Trans. Microwave Theory Tech., 1993, Vol. 41, Issue 10.

2. P. Focardi, R. Mc Grath, A. Neto "Design Guidelines for $\mathrm{THz}$ mizers and Detectors", IEEE Trans. on MTT, Vol. 53, no. 5 May 2005

3. $\mathrm{Wu}, \mathrm{X}$.; Eleftheriades, G.V.; van Deventer-Perkins, T.E.; Design and characterization of single- and multiple-beam mm-wave circularly polarized substrate lens antennas for wireless communications Microwave Theory and Techniques, IEEE Transactions on Vol. 49, No. 3, March 2001 Page(s):431 441

4. Nuria Llombart, Andrea Neto, Giampiero Gerini, Magnus Bonnedal, Peter De Maagt, "Leaky Wave Enhanced Feed Arrays for the Improvement of the Edge of Coverage Gain in Multi Beam Reflector Arrays", accepted for publication on IEEE Transactions on Antennas and Propagation,

5. A. Neto, N. Llombart, G. Gerini, M. Bonnedal, P. de Maagt, "EBG Enhanced Feeds for High Aperture Efficiency Reflector Antennas", on the IEEE Transactions of Antennas and Propagation, Vol. 55, no.7, August 2007

6. D. R. Jackson, A. A. Oliner, "A leaky-wave analysis of the high-gain printed antenna configuration", IEEE Transactions on Antennas and Propagation, Vol. 36, no. 7, pp. 905-909, July 1988. 